\title{
DIREITO À SAÚDE EM PORTUGAL: DELIMITAÇÃO JURÍDICA DO SERVIÇO NACIONAL DE SAÚDE
}

\author{
ALEXANDRE MORAIS NUNES
}

\begin{abstract}
Doutor em Administração da Saúde. Professor Auxiliar Convidado do Instituto Superior de Ciências Sociais e Políticas (ISCSP) - Universidade de Lisboa, Lisboa, Portugal. Investigador do Centro de Administração e Políticas Públicas, ISCSP-ULisboa. E-mail: <anunes@iscsp.ulisboa.pt>.
\end{abstract}

Resumo: 0 direito à saúde em Portugal está delimitado por uma base legal, consagrada na Constituição da República portuguesa de 1976, que se materializou em 1979 através da criação de um Serviço Nacional de Saúde, que presta cuidados de forma universal, geral e tendencialmente gratuita. Este artigo, através de uma revisão da legislação publicada e da literatura, pretende dar a conhecer o enquadramento legal da saúde em Portugal, respetiva evolução ao longo dos anos e delimitação jurídica atual.

Palavras-chave: Serviço Nacional de Saúde. Constituição da República portuguesa. Direito à saúde.

Sumário: Introdução -10 direito constitucional à saúde -2 A criação de um Serviço Nacional de Saúde - 3 A universalidade e generalidade do acesso ao SNS - 4 A gratuidade no financiamento no SNS - Conclusões - Referências

\section{Introdução}

O direito à saúde em Portugal foi integrado em 1976 na Constituição da República portuguesa, que se mantém vigente na redação atual datada no ano 2005. ${ }^{1}$

A República portuguesa tem uma Constituição que se assenta no Estado Social e Democrático de Direito, que apresenta valores de liberdade, direitos fundamentais e direitos sociais. Nesta medida, todas as prestações sociais idealizadas pelos legisladores constituem concretizações de um dever de base

1 Cf. PORTUGAL. Lei no 1/2005, de 12 de agosto. Lisboa, 2005. 
constitucional e não qualquer vontade política em retirar ou atribuir benefícios aos cidadãos.

O direito à saúde é um dos direitos sociais que aparece consagrado no $64^{\circ}$ artigo da Constituição e constitui a base dos princípios em que se fundou o Serviço Nacional de Saúde (SNS). ${ }^{2}$

O SNS é a concretização do dever do Estado em garantir o direito à proteção da saúde dos seus cidadãos. Na sua redação original, o Serviço Nacional de Saúde garante uma prestação universal, geral e gratuita, que pelo fato de revestir uma imposição constitucional tem vitalidade, durabilidade, independência e subsistência que vai muito além da vontade política do Governo. ${ }^{3}$

Como Estado de Direito fundamental, a prestação pública de cuidados de saúde realizada pelas unidades do SNS respeitam o acesso individual, a proteção a todos os cidadãos (particularmente aos mais desfavorecidos, mulheres grávidas, crianças, adolescentes e pessoas em posição econômico-social mais desfavorecida), a promoção de melhores condições nas prestações de saúde com segurança e qualidade nos cuidados de saúde primários (inclui atividades de promoção e prevenção da saúde), hospitalares (prestação de cuidados mais especializados e diferenciados com meios de diagnósticos e terapêutica), continuados (para reabilitar e recuperar) e paliativos (no final de vida). ${ }^{4}$

A opção política, não colocando em causa o direito constitucional à saúde nem retirando qualquer norma aos direitos fundamentais e garantindo o cumprimento das funções de proteção e promoção da prestação de cuidados de saúde é acomodável às prioridades governativas, de acordo com as necessidades dos cidadãos. O Governo define, a cada ano, a sua estratégia para a política de saúde nacional, em que poderá eventualmente realizar uma maior aposta em um ou outros níveis de cuidados, não prejudicando ou reduzindo a prestação dos restantes nem pondo em causa as insígnias constitucionais.

No entanto, sendo o Serviço Nacional de Saúde uma imposição constitucional, em termos jurídicos, o poder político tem atuação e domínio limitados, e o caso de limitação ou risco de limitação da prestação de cuidados constitui não cumprimento da lei, punido judicialmente. ${ }^{5}$

Numa última instância, a ação política é sujeita à análise, avaliação e julgamento realizados pelo Tribunal Constitucional, que garantem a constitucionalidade

Cf. CAMPOS, António. Reformas na saúde - O fio condutor. Coimbra: Almedina, 2008.

Cf. NOVAIS, Jorge Reis. Constituição e serviço nacional de saúde. Direitos Fundamentais \& Justiça, v. 4, n. 11, p. 85-109, abr./jun. 2010.

4 Cf. FERNANDES, Adalberto. A combinação público-privado em saúde: impacto no desempenho no sistema e nos resultados em saúde no contexto português. Lisboa: Universidade de Lisboa, 2015.

5 Cf. NOVAIS, Jorge Reis. Os princípios constitucionais estruturantes. Coimbra: Almedina, 2011. 
dos atos públicos e definem a limitação jurídica da reforma a realizar no Serviço Nacional de Saúde. Este tribunal, por norma, tem sido ouvido para verificar a conformidade e compatibilidade constitucional de algumas opções políticas legisladas. Durante a existência do SNS, foram já alvo da intervenção do Tribunal Constitucional várias questões, desde a questão da existência do SNS à sua generalidade, assim como questões da gratuidade e financiamento revestidas na última redação pelo termo "tendencialmente gratuito". Dessas análises resultou um conjunto de acórdãos do Tribunal Constitucional. ${ }^{6}$

Este artigo tem como objetivo dar a conhecer o enquadramento legal e delimitações constitucionais do direito à saúde, sua evolução, enquadramento e direitos e deveres declarados. Também aborda a concretização dos pressupostos pela criação do Serviço Nacional de Saúde, caracterizando este serviço público com relação aos princípios de universalidade e generalidade no acesso e de tendencial gratuidade no financiamento, e contrapondo a redação legal e a prática com as análises a delimitações jurídicas baseadas nos acórdãos emitidos pelo Tribunal Constitucional.

\section{0 direito constitucional à saúde}

O modelo de Estado Social e de Direito Democrático está presente em Portugal e encontra-se legislado através da Constituição da República portuguesa há já 40 anos.

A Constituição da República garante no seu art. 18ํum conjunto de preceitos constitucionais respeitantes aos direitos, liberdades e garantias aplicáveis a todas as entidades (públicas e privadas), que só podem ser restritos em casos muito específicos e previstos na sua redação e têm de configurar um caráter geral e abstrato, não podem diminuir a extensão e o alcance do conteúdo essencial dos preceitos constitucionais.

O direito de proteção à saúde é um direito social previsto no art. $64^{\circ}$ da Constituição. Na sua redação original, ${ }^{7}$ reconhecia o direito à proteção da saúde a todos os cidadãos e o dever de defender e promover (art. 1ํํ) e estipulava que esse direito seria realizado pela criação de um serviço nacional de saúde universal, geral e gratuito (art. $2^{\circ}$ ). Para tal, preconizava a criação das necessárias condições econômicas, sociais e culturais que permitissem a proteção da infância,

6 Cf. NOVAIS, Jorge Reis. Constituição e serviço nacional de saúde. Direitos Fundamentais \& Justiça, v. 4, n. 11, p. 85-109, abr./jun. 2010.

Cf. PORTUGAL. Decreto de 10/04 de 1976. Lisboa, 1976. 
da juventude e da velhice e a melhoria sistemática das condições de vida e de trabalho, bem como a promoção da cultura física e esportiva, escolar e ainda o desenvolvimento da educação sanitária do povo.

No cumprimento dos objetivos expostos e para assegurar determinantemente o direito à proteção da saúde, a Constituição é clara, atribuindo as prioridades incumbidas ao Estado, entre as quais se destacam:

- garantia de acesso a todos os cidadãos, independentemente da sua condição econômica, aos cuidados da medicina preventiva (atual atenção primária à saúde), curativa (atuais cuidados de saúde hospitalares/diferenciados e especializados) e de reabilitação (atuais cuidados continuados de convalescença, reabilitação e manutenção);

- garantia racional de eficiente cobertura médica e hospitalar de todo o país (através de uma rede de prestadores);

- orientação à sua ação para a socialização da medicina e dos sectores médico-medicamentosos;

- articulação dos prestadores empresariais e privadas da medicina, com um serviço nacional de saúde;

- controle da produção, comercialização e uso dos produtos químicos, biológicos e farmacêuticos e outros meios de tratamento e diagnóstico (art. 3oㅡ).

A redação original do art. $64^{\circ}$, que confere o direito à saúde, dada pelo Decreto de 10.4.1976, sofreu três alterações: a primeira em 1982, a segunda em 1989 e a terceira em 1997.

A primeira revisão constitucional realizada no ano de 1982 contemplou a segunda versão do art. 64․ Relativamente à redação inicial, a Lei no 1/82, de 30 de setembro, no seu art. 54ํ, aditou um nำ 4, com a seguinte redação: "O Serviço Nacional de Saúde tem gestão descentralizada e participada". Esta alteração retrata a criação das Administrações Regionais de Saúde, em cinco regiões do país (Norte, Centro, Lisboa e Vale do Tejo, Alentejo e Algarve), que têm a responsabilidade realizar planejamento, alocar fundos, gerir recursos humanos, fornecer apoio administrativo e técnico às unidades de saúde, implementar objetivos da política de saúde e monitorizar o desempenho dos prestadores públicos.

Com a segunda revisão constitucional e segunda revisão do art. 64ํㅜ, realizaram-se alterações mais profundas relativamente à redação inicial. A Lei Constitucional $n^{\circ} 1 / 89$, de 8 de julho, afastou o princípio da gratuidade $(n \circ 2$ do art. 64을 e da finalidade a atingir (alínea "c") do no 3 do art. 64․․ Assim, os nos 2 e 3 do art. 64ำ passaram a ter as seguintes redações (art. 36으 da Lei no 1/89, de 8 de julho): 
2. O direito à proteção da saúde é realizado:

a) Através de um serviço nacional de saúde universal e geral e, tendo em conta as condições econômicas e sociais dos cidadãos, tendencialmente gratuito;

b) Pela criação de condições econômicas, sociais e culturais que garantam a proteção da infância da juventude e da velhice e pela melhoria sistemática das condições de vida e de trabalho, bem como pela promoção da cultura física e esportiva, escolar e popular e ainda pelo desenvolvimento da educação sanitária do povo.

3. Para assegurar o direito à proteção da saúde, incumbe prioritariamente ao Estado:

a) $[\ldots]$

b) $[\ldots]$

c) Orientar a sua ação para a socialização dos custos dos cuidados médicos e medicamentosos.

Em 1997, com a quarta revisão constitucional ocorreu a última alteração do art. 64ํ. Com a publicação da Lei no 1/97, de 20 de setembro, foram feitas alterações nos nำs 2 e 3:

1. Na alínea b) do no 2 do art. 64ํ da Constituição, é aditada a expressão 'e ambientais' entre 'culturais' e 'que garantam', a expressão 'designadamente' entre 'garantam' e 'a proteção' e, in fine, a expressão 'e de práticas de vida saudável;

2. Na alínea b) do no 3, é eliminada a expressão 'médica e hospitalar' e aditada, in fine, a expressão 'em recursos humanos e unidades de saúde'.

3. Na alínea d) do no 3, a expressão 'controlar' é substituída por 'fiscalizar', sendo aditada, in fine, a expressão 'por forma a assegurar, nas instituições de saúde públicas e privadas, adequados padrões de eficiência e de qualidade'.

4. Na alínea e) do no 3, é aditada a expressão 'a distribuição' entre 'a produção' e 'a comercialização'.

5. No no 3 é aditada uma nova alínea f), com a seguinte redação: Estabelecer políticas de prevenção e tratamento da toxicodependência. 
Com estas alterações fechou-se o art. 64ํqu, na sua última revisão, a oitava, ${ }^{8}$ apresenta a seguinte redação:

1. Todos têm direito à proteção da saúde e o dever de a defender e promover.

2. O direito à proteção da saúde é realizado:

a) Através de um serviço nacional de saúde universal e geral e, tendo em conta as condições econômicas e sociais dos cidadãos, tendencialmente gratuito;

b) Pela criação de condições econômicas, sociais, culturais e ambientais que garantam, designadamente, a proteção da infância, da juventude e da velhice, e pela melhoria sistemática das condições de vida e de trabalho, bem como pela promoção da cultura física e desportiva, escolar e popular, e ainda pelo desenvolvimento da educação sanitária do povo e de práticas de vida saudável.

3. Para assegurar o direito à proteção da saúde, incumbe prioritariamente ao Estado:

a) Garantir o acesso de todos os cidadãos, independentemente da sua condição econômica, aos cuidados da medicina preventiva, curativa e de reabilitação;

b) Garantir uma racional e eficiente cobertura de todo o país em recursos humanos e unidades de saúde;

c) Orientar a sua ação para a socialização dos custos dos cuidados médicos e medicamentosos;

d) Disciplinar e fiscalizar as formas empresariais e privadas da medicina, articulando-as com o serviço nacional de saúde, por forma a assegurar, nas instituições de saúde públicas e privadas, adequados padrões de eficiência e de qualidade;

e) Disciplinar e controlar a produção, a distribuição, a comercialização e o uso dos produtos químicos, biológicos e farmacêuticos e outros meios de tratamento e diagnóstico;

f) Estabelecer políticas de prevenção e tratamento da toxicodependência.

4. O serviço nacional de saúde tem gestão descentralizada e participada.

8 Cf. PORTUGAL. Lei no 1/2005, de 12 de agosto. Lisboa, 2005. 
Pela análise da redação constitucional, o Estado tem de conferir a os cidadãos o direito à promoção, proteção e defesa da saúde. No caso de incumprimento destas obrigações, o Estado comete uma inconstitucionalidade por omissão, que está prevista também na Constituição da República portuguesa no seu art. 283ㅇ․ O controle dessa inconstitucionalidade pertence aos tribunais (art. 277으) e, em especial, ao Tribunal Constitucional (art. 221ํㅜ).

A fiscalização da inconstitucionalidade na jurisprudência portuguesa pode realizar-se de várias formas: abstrata-preventiva, abstrata-sucessiva ou concreta. A primeira ocorre quando se realiza antes da norma entrar em vigor e é atribuída de forma exclusiva ao Tribunal Constitucional pelo presidente da República, primeiroministro, ministros da República ou por um 1/5 dos deputados da Assembleia da República. A segunda (abstrata-sucessiva) desenvolve-se quando se realiza depois da entrada em vigor e por último a fiscalização concreta ocorre quando a fiscalização é colocada durante um processo a decorrer em tribunal.

\section{A criação de um Serviço Nacional de Saúde}

Em função do cumprimento dos direitos fundamentais inscritos na Constituição da República, o Estado tem o dever de proteger a saúde dos cidadãos, respeitando o acesso individual e coletivo ao bem protegido (neste caso a saúde) e criando todas as condições para garantir o acesso universal, sem qualquer impedimento e independente de cor, religião, deficiência ou limitação física, otimizando todas as condições necessárias para proporcionar um acesso com qualidade e com as respostas necessárias em termos de promoção da saúde, prevenção da doença, vertente curativa ou de reabilitação.

Em conformidade com o fundamento na alínea "a" do № 2 do art. 64을 da Constituição portuguesa, foi criado no ano de 1979 um Serviço Nacional de Saúde (SNS). Esta foi a primeira materialização da constituição no que respeita ao setor da saúde que garante o direito à proteção da saúde de forma universal, geral e gratuita.

O SNS é constituído pela rede de órgãos e serviços que, na dependência do Ministério da Saúde, atuam de forma articulada e sob direção unificada, gestão descentralizada, desconcentrada e democrática, que visa à prestação de cuidados globais de saúde a toda a população. Assim, o Serviço Nacional de Saúde goza de autonomia administrativa e financeira e compreende órgãos centrais, regionais e locais, dispondo de serviços prestadores de cuidados primários e serviços prestadores de cuidados diferenciados, de acordo com o art. 18음 Lei no 56/79, de 15 de setembro. 
O SNS deve assegurar a distribuição racional, a hierarquização técnica e o funcionamento coordenado dos serviços, definindo a complementaridade de valências e a promoção da descentralização decisória com a participação dos pacientes no planejamento e na gestão dos serviços (art. 19ำ da Lei no 56/79, de 15 de setembro). Para o cumprimento destes objetivos, os órgãos centrais do SNS dedicam-se ao estudo da população, a propor uma política de saúde, à avaliação e ao planejamento da prestação de serviços, à definição e implementação de normas, à inspeção e coordenação com outros setores. Porém, no contexto descentralizado, os órgãos regionais executam a política de saúde, registam dados epidemiológicos e estão responsáveis pela inspeção dos serviços, pelo controle do exercício profissional, pelo planejamento local, pela formação e investigação em saúde e, ainda, pela celebração de convênios regionais com entidades não integradas do SNS (setor privado e convencional) (arts. 20ํe 21ํ da Lei no 56/79, de 15 de setembro).

Pelo fato de ser uma imposição constitucional, independentemente da vontade política em exercício de poder e da opinião política, a subsistência do SNS está juridicamente protegida e reforçada pelo poder constitucional. Neste sentido, o Tribunal Constitucional é a entidade encarregada de salvaguardar, em última instância, a constitucionalidade das políticas de saúde. Nos pontos seguintes analisam-se, à luz da legislação e dos acórdãos do Tribunal Constitucional, os princípios-base de universalidade, generalidade e tendencial gratuidade que caracterizam a essência do Serviço Nacional de Saúde. ${ }^{9}$

\section{A universalidade e generalidade do acesso ao SNS}

Ao direito à proteção da saúde universal e geral garantida pelo Estado através do Serviço Nacional de Saúde corresponde o dever incumbido a todos os cidadãos de a defender e promover.

A universalidade no acesso traduz-se na garantia de prestação de cuidados a todos os cidadãos, independentemente da sua condição econômica e social. Também, o acesso está aos cidadãos estrangeiros, em regime de reciprocidade, aos apátridas e aos refugiados políticos que residam ou se encontrem em território nacional (art. 4ํ da Lei ํㅜ 56/79, de 15 de setembro).

O direito à saúde é um direito social, ou seja, um direito de todos os cidadãos independentemente da sua condição econômica, e é um dever do Estado realizar

9 Cf. NOVAIS, Jorge Reis. Constituição e serviço nacional de saúde. Direitos Fundamentais \& Justiça, v. 4, n. 11, p. 85-109, abr./jun. 2010. 
a prestação desse direito da melhor forma e com a máxima eficácia. No entanto, compreende-se que a política de saúde realize ações especificas para grupos de cidadãos mais desfavorecidos, pelo que as obrigações do Estado variam consoante as diferentes carências e necessidades dos cidadãos, o que não compromete a universalidade no acesso. Portanto, a titularidade da prestação é universal, mas os deveres do Estado, nomeadamente o dever de promover, poderão por estes motivos ser diferenciados. ${ }^{10}$

No âmbito desta universalidade do acesso, é concedida aos cidadãos a liberdade de escolha do responsável pela prestação de cuidados de saúde, dentro dos condicionalismos econômicos e das normas de distribuição racional e regionalização dos serviços.

A generalidade da prestação incorre do fato de o SNS envolver uma prestação completa, com todos os cuidados integrados de saúde - desde as atividades de promoção e vigilância da saúde, prevenção da doença (cuidados de saúde primários), diagnóstico e tratamento dos doentes (cuidados de saúde hospitalares) e reabilitação médica e social (cuidados continuados) - assegurados, em princípio, pelos estabelecimentos da rede oficial do Serviço Nacional de Saúde (arts. 6으 e 15으 da Lei no 56/79, de 15 de setembro). No entanto, quando não for possível garantir que todas as prestações de saúde sejam realizadas por esta rede, o acesso poderá ser realizado por entidades não integradas concessionadas ou excecionalmente por reembolso direto ao beneficiário ( $\mathrm{n}^{\circ} 2$ do art. 15을 da Lei oㅡ $56 / 79$, de 15 de setembro). De acordo com Miranda e Medeiros, ${ }^{11}$ isto significa que, uma vez que em complemento é possível recorrer a serviços privados, o SNS garante a cobertura em todos os domínios e prestações de cuidados de saúde.

A garantia de prestação compreende o acesso a todas as prestações do SNS e não sofre restrições exceto "as impostas pelo limite de recursos humanos, técnicos e financeiros disponíveis” (no 2 do art. 6으 da Lei no 56/79, de 15 de setembro).

Apesar de, em termos jurídicos, a atuação dos poderes políticos estar limitada num SNS cuja existência passou a ser uma imposição constitucional, em 1984 houve uma tentativa, por diploma do Governo, de revogar uma importante parte da

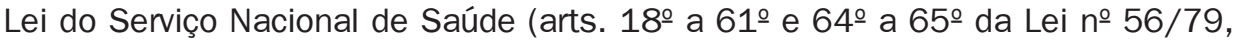
de 15 de setembro). No âmbito da fiscalização abstrata da constitucionalidade e da legitimidade prevista nos arts. $281^{\circ}$ e $282^{\circ}$ da Constituição da República portuguesa, a pedido do presidente da República, o Tribunal Constitucional

10 Cf. NOVAIS, Jorge Reis. Constituição e serviço nacional de saúde. Direitos Fundamentais \& Justiça, v. 4, n. 11, p. 85-109, abr./jun. 2010.

11 Cf. MIRANDA, Jorge; MEDEIROS, Rui. Constituição portuguesa anotada. Coimbra: Almedina, 2005. v. I. 
analisou a alteração legislativa e declarou a inconstitucionalidade desta iniciativa política, na medida que, tratando-se o SNS de uma imposição constitucional, a revisão do seu diploma nos termos apresentados constituía um retrocesso, equivalente à destruição ou inutilização do Serviço Nacional de Saúde, o que induzia um incumprimento do art. 64ํ da Constituição da República portuguesa. ${ }^{12}$

Esta decisão foi muito controversa, pelo fato de se demarcar a proibição do retrocesso:

\begin{abstract}
Se a Constituição impõe ao Estado a realização de uma determinada tarefa - a criação de uma certa instituição, uma determinada alteração na ordem jurídica -, então, quando ela seja levada a cabo, o resultado passa a ter a proteção direta da Constituição. O Estado não pode voltar atrás, não pode descumprir o que cumpriu, não pode tornar a colocar-se na situação de devedor. ${ }^{13}$
\end{abstract}

Por este fato, até aos dias de hoje mais nenhum Governo tomou a iniciativa de propor uma alteração de raiz à lei que cria o Serviço Nacional de Saúde, cujas bases constitucionalmente definidas pautam a sua atuação até à atualidade.

Sobre a jurisprudência constitucional, os princípios de universalidade e generalidade saem reforçados deste acórdão, ${ }^{14}$ dado que fico bem expresso na declaração de votos que o legislador "fica obrigado a assegurar aos cidadãos, ao menos, o conteúdo mínimo do direito à proteção da saúde - além do mais -, criando um serviço nacional de saúde universal, geral e gratuito". ${ }^{15}$

A universalidade do acesso e a generalidade da provisão permanecem inalteradas, desde a primeira versão da redação constitucional de 1976, e sem uma prévia revisão da Constituição não será possível condicionar, excluir ou restringir o acesso aos cidadãos. ${ }^{16}$

A admissão de um doente num subsistema de saúde ou a sua adesão a um seguro de saúde privada não Ihe retira qualquer direito no âmbito da prestação

12 Cf. TRIBUNAL CONSTITUCIONAL. Acórdão no 39/84, de 5 de maio. Lisboa, 1984; CANOTILHO, J. Gomes; MOREIRA, Vital. Constituição da República portuguesa anotada. 3. ed. Coimbra: Coimbra, 2007; MIRANDA, Jorge; MEDEIROS, Rui. Constituição portuguesa anotada. Coimbra: Almedina, 2005. v. I; VALE, Luís Meneses do. A jurisprudência do Tribunal Constitucional sobre o acesso às prestações concretizadoras do direito à protecção da saúde: alguns momentos fundamentais. Jurisprudência Constitucional, Coimbra, n. 12, p. 12-47, 2006.

13 TRIBUNAL CONSTITUCIONAL. Acórdão no 39/84, de 5 de maio. Lisboa, 1984.

14 Cf. VALE, Luís Meneses do. A jurisprudência do Tribunal Constitucional sobre o acesso às prestações concretizadoras do direito à protecção da saúde: alguns momentos fundamentais. Jurisprudência Constitucional, Coimbra, n. 12, p. 12-47, 2006.

15 Cf. TRIBUNAL CONSTITUCIONAL. Acórdão no 39/84, de 5 de maio. Lisboa, 1984.

16 Cf. CANOTILHO, J. Gomes; MOREIRA, Vital. Constituição da República portuguesa anotada. 3. ed. Coimbra: Coimbra, 2007. 
de cuidados de saúde no SNS, pelo que em caso algum é possível aplicar-se uma imposição estatal para saída de um cidadão da prestação de cuidados realizada no SNS. ${ }^{17}$

\section{A gratuidade no financiamento no SNS}

Em sua formulação original, o acesso ao Serviço Nacional de Saúde era gratuito para todos os utilizadores que já contribuíam para o Estado através dos seus impostos. No entanto, o diploma ressalvava à partida a implementação da contribuição de parte da despesa com a prestação de saúde, explícita no seu art. 7우 "O acesso ao SNS é gratuito, sem prejuízo do estabelecimento de taxas moderadoras diversificadas tendentes a racionalizar a utilização das prestações".

Dez anos após a implementação do Serviço Nacional de Saúde, a revisão constitucional de 1989 deixou cair a gratuidade no acesso às prestações. A esta data, foi do entendimento do legislador alterar a primeira alínea do no 2 do art. 64ํㅜ passando a prestação de cuidados a ser realizada através de “um serviço nacional de saúde universal e geral e, tendo em conta as condições econômicas e sociais dos cidadãos, tendencialmente gratuito".

O alcance desta alteração teve repercussões com a implementação do pagamento de taxas moderadoras, que se efetivou um ano após a revisão constitucional de 1989 com a publicação da Lei de Bases da Saúde. ${ }^{18} \mathrm{Na}$ base XXXIV deste diploma, é referido que o objetivo da implementação das taxas moderadoras foi "completar as medidas reguladoras do uso dos serviços de saúde, podem ser cobradas taxas moderadoras", estipulando que estariam isentos os "grupos populacionais sujeitos a maiores riscos e os financeiramente mais desfavorecidos".

Contudo, o Tribunal Constitucional pronunciou-se sobre este tema no Acórdão no 731/95, dando a percepção de que a implementação da tendencial gratuidade não era alvo de inconstitucionalidade, mas sim de uma flexibilização da redação original, ${ }^{19}$ provavelmente pelo fato de a Lei do SNS já contemplar a possibilidade de se pagarem taxas moderadoras e estas serem apenas uma forma de racionalização da utilização dos serviços, não o pagamento das prestações de saúde, e pelo

17 Cf. NOVAIS, Jorge Reis. Constituição e serviço nacional de saúde. Direitos Fundamentais \& Justiça, v. 4, n. 11, p. 85-109, abr./jun. 2010.

18 Cf. PORTUGAL. Lei no 47/90, de 24 de agosto. Lisboa, 1990.

19 Cf. NOVAIS, Jorge Reis. Constituição e serviço nacional de saúde. Direitos Fundamentais \& Justiça, v. 4, n. 11, p. 85-109, abr./jun. 2010. 
fato de não se aplicarem aos cidadãos desfavorecidos economicamente. ${ }^{20} \mathrm{Com}$ a tendencial gratuidade, reforçou-se a aplicação de taxas moderadoras por parte do paciente nas prestações.

A crítica surgiu em torno desta questão, pelo fato de saber que a exigência do pagamento diferenciado aos cidadãos será ou não incompatível com os limites constitucionais de universalidade. No entanto, o Tribunal Constitucional assim não o entendeu. ${ }^{21}$

A questão da constitucionalidade da aplicação das taxas moderadoras foi colocada em causa logo após a publicação da Lei do SNS, tendo sido pedido em 1982 um parecer à Comissão Constitucional (Parecer no 35/82), que justificou que a gratuidade foi de tipo eminentemente programática e progressiva, o que ia ao encontro das regras constitucionais. Contudo, não satisfeito com esta justificação, o Tribunal Constitucional avaliou o tema e no Acórdão ํㅜ 330/89, de 11 de abril, pronunciou-se referindo que, mesmo concebida de forma imediata, não constitui uma inconstitucionalidade a aplicação de taxas moderadoras pagas pelos pacientes do Serviço Nacional de Saúde. No fundamento desta conclusão, o Tribunal Constitucional entende a gratuidade como um conceito normativo com "um certo halo de indeterminação" do legislador, pelo fato de não significar que o paciente não teria de pagar qualquer contrapartida, mas sim para salvaguardar o individual e total suporte da prestação, evitando que o pagamento do serviço fosse imposto ao cidadão. A este fato acrescentou-se a justificação da aplicação de taxas com objetivos de racionalização de funcionamento do SNS atuando no lado da procura de cuidados como uma forma de dissuasão do acesso abusivo e sem justificação aos serviços de saúde. ${ }^{22}$

Atualmente, as taxas moderadoras são cobradas no acesso a consultas nos prestadores de cuidados de saúde primários, no domicílio, nos hospitais e em outros estabelecimentos de saúde públicos ou privados convencionadas (com acordos de cooperação com o SNS), na realização de exames complementares de diagnóstico e terapêutica em serviços de saúde públicos ou privados convencionados (com exceção dos efetuados em regime de internamento, no hospital de dia) e no atendimento nos serviços de urgência para o qual existe encaminhamento pela rede de prestação de cuidados de saúde primários, pelo

20 Cf. NOVAIS, Jorge Reis. As restrições aos direitos fundamentais não expressamente autorizadas pela Constituição. Coimbra: Almedina, 2003.

21 Cf. NOVAIS, Jorge Reis. Direitos fundamentais: trunfos contra a maioria. Coimbra: Almedina, 2006.

22 Cf. NOVAIS, Jorge Reis. Constituição e serviço nacional de saúde. Direitos Fundamentais \& Justiça, v. 4, n. 11, p. 85-109, abr./jun. 2010. 
centro de atendimento do Serviço Nacional de Saúde (serviço telefónico) ou pelo Instituto Nacional de Emergência Médica (INEM). ${ }^{23}$

Essas taxas, podendo restringir o acesso, seriam inconstitucionais. Por este motivo e para deixar claro na lei, os decretos-lei que regulam a fixação de taxas moderadoras apresentam uma diferenciação em três categorias: os pacientes isentos, não isentos ou dispensados do pagamento. ${ }^{24}$

Para além dos usuários que preencham os requisitos para o reconhecimento da situação de insuficiência econômica, e no decurso da alteração legislativa aqui referida, encontram-se isentos do pagamento de taxas moderadoras, nos termos do art. 4을 do Decreto-Lei № 113/2011, de 29 de novembro, alterado pela Lei no 7-A/2016, de 30 de março, os seguintes pacientes:

a) as grávidas e parturientes;

b) os menores;

c) os pacientes com grau de incapacidade igual ou superior a $60 \%$;

d) os pacientes em situação de insuficiência econômica, bem como os dependentes do respetivo agregado familiar;

e) os doadores benévolos de sangue;

f) os doadores vivos de células, tecidos e órgãos;

g) os bombeiros;

h) os doentes transplantados;

i) os militares e ex-militares das Forças Armadas que, em virtude da prestação do serviço militar, se encontrem incapacitados de forma permanente;

j) os desempregados com inscrição válida no Centro de Emprego, auferindo subsídio de desemprego igual ou inferior a 1,5 vezes o indexante de apoios sociais (IAS) que, em virtude de situação transitória ou de duração inferior a um ano, não podem comprovar a sua condição de insuficiência econômica em tempo, por via dos critérios estabelecidos na Portaria no 311-D/2011, de 27 de dezembro, bem como o respetivo cônjuge e dependentes;

k) os jovens em processo de promoção e proteção a correr termos em comissão de proteção de crianças e jovens ou no tribunal, com medida aplicada no âmbito do art. 35ㅇ da Lei de Proteção de Crianças e Jovens em Perigo, aprovada pela Lei № 147/99, de 1 de setembro, alterada pela Lei no 31/2003, de 22 de agosto, que não possam, por qualquer forma, comprovar a sua condição de insuficiência econômica;

23 Cf. ADMINISTRAÇÃO CENTRAL DO SISTEMA DE SAÚDE (ACSS). Circular normativa no 8 - Alteração do regulamento de aplicação de taxas moderadoras. Lisboa: Ministério da Saúde, 2016.

24 Cf. SIMÕES, Jorge; BARROS, Pedro; PEREIRA, João. A sustentabilidade financeira do Serviço Nacional de Saúde. Lisboa: Ministério da Saúde, 2008. 
I) os jovens que se encontrem em cumprimento de medida tutelar de internamento, de medida cautelar de guarda em centro educativo ou de medida cautelar de guarda em instituição pública ou privada, por decisão proferida no âmbito da Lei Tutelar Educativa, aprovada pela Lei no 166/99, de 14 de setembro, alterada pela Lei no 4/2015, de 15 de janeiro, que não possam, por qualquer forma, comprovar a sua condição de insuficiência econômica;

m) os jovens integrados em qualquer das respostas sociais de acolhimento por decisão judicial proferida em processo tutelar cível, e nos termos da qual a tutela ou o simples exercício das responsabilidades parentais sejam deferidos à instituição à qual os jovens se encontram integrados, que não possam, por qualquer forma, comprovar a sua condição de insuficiência econômica;

n) os requerentes de asilo e refugiados e respetivos cônjuges ou equiparados e descendentes diretos. ${ }^{25}$

Nos termos do art. 8을 do Decreto-Lei no 113/2011 de 29 de novembro, alterado pela Lei no 7-A/2016, é dispensada a cobrança de taxas moderadoras num conjunto de procedimentos associados a questões de saúde pública, e a situações clínicas e riscos de saúde que impliquem especial e recorrente necessidade de cuidados de saúde:

a) consultas de planejamento familiar e atos complementares prescritos no decurso destas;

b) consultas, bem como atos complementares prescritos no decurso destas no âmbito de doenças neurológicas degenerativas e desmielinizantes, distrofias musculares, tratamento da dor crónica, saúde mental, deficiências congénitas de fatores de coagulação, infeção pelo vírus da imunodeficiência humana (Aids), diabetes, tratamento e seguimento da doença oncológica;

c) primeira consulta de especialidade hospitalar, com referenciação pela rede de prestação de cuidados de saúde primários;

d) cuidados de saúde respiratórios no domicílio;

e) cuidados de saúde na área da diálise;

f) consultas e atos complementares necessários para as dádivas de células, sangue, tecidos e órgãos;

25 Cf. ADMINISTRAÇÃO CENTRAL DO SISTEMA DE SAÚDE (ACSS). Circular normativa $n^{\circ} 8$ - Alteração do regulamento de aplicação de taxas moderadoras. Lisboa: Ministério da Saúde, 2016. p. 7-8. 
g) atos complementares de diagnóstico realizados no decurso de rastreios organizados de base populacional e de diagnóstico neonatal, promovidos no âmbito dos programas de prevenção da Direção-Geral da Saúde;

h) consultas no domicílio realizadas por iniciativa dos serviços e estabelecimentos do SNS;

i) atendimentos urgentes e atos complementares decorrentes de atendimentos a vítimas de violência doméstica;

j) programas de tratamento de alcoólicos crónicos e toxicodependentes;

k) programas de tomas de observação direta;

I) vacinação prevista no programa nacional de vacinação e pessoas abrangidas pelo programa de vacinação contra a gripe sazonal;

m) atendimento em serviço de urgência, no seguimento de:

1. encaminhamento pela rede de prestação de cuidados de saúde primários, pelo Centro de Atendimento do Serviço Nacional de Saúde e pelo Inem para um serviço de urgência, incluindo os atos complementares prescritos;

2. admissão de internamento através da urgência.

n) atendimento na rede de prestação de cuidados de saúde primários, no seguimento de encaminhamento pelo Centro de Atendimento do Serviço Nacional de Saúde. ${ }^{26}$

O contributo das taxas moderadoras não é significativo para a despesa em saúde, representando cerca de $1 \%$ do total da despesa pública em saúde. Por esse motivo, o grande financiador do Serviço Nacional de Saúde é o Estado através de dotações anuais do Orçamento Geral do Estado, resultante da contribuição dos impostos de todos os cidadãos ativos, que ronda os 9.000 milhões de euros. ${ }^{27}$

\section{Conclusões}

Em Portugal impera um Estado Social que garante uma proteção a todos os cidadãos nas mais variadas prestações sociais nas quais se inclui o direito à proteção da saúde, que está consagrado na Constituição da República portuguesa.

A proteção do direito à saúde materializou-se através da criação de um Serviço Nacional de Saúde, que presta cuidados de saúde de forma universal a todos os

26 Cf. ADMINISTRAÇÃO CENTRAL DO SISTEMA DE SAÚDE (ACSS). Circular normativa no 8 - Alteração do regulamento de aplicação de taxas moderadoras. Lisboa: Ministério da Saúde, 2016. p. 14-15.

27 Cf. CAMPOS, Correia de; RAMOS, Francisco. Contas e ganhos na saúde em Portugal. Dez anos de percurso. Desafios para Portugal. Lisboa: Presidência da República, 2005; NUNES, Alexandre. Reformas na gestão hospitalar. na análise dos efeitos da empresarialização. Lisboa: Universidade de Lisboa, 2016. 
cidadãos, integrando todas as prestações de saúde (atenção primária, hospitalar, de reabilitação e paliação) e de forma tendencialmente gratuita. Assim, o Estado respeita o acesso para todos os cidadãos, conferindo a isenção e dispensa do pagamento para alguns casos específicos.

Em conclusão à análise realizada, não há dúvidas de que a proteção da saúde em Portugal é um direito inalienável que assiste os cidadãos. Relativamente às limitações jurídicas do direito à saúde, assim, há a destacar a tendência para a gratuidade que foi integrada com a revisão constitucional de 1989. No entanto, ficou definida uma isenção e dispensa de pagamento para casos específicos, particularmente pensada nos pacientes com dificuldades econômicas que não poderiam ficar restringidos do acesso por este motivo, o que seria considerado inconstitucional.

A leitura da Constituição permite ainda concluir que não há nenhuma condição que impeça o cumprimento do dever do Estado de salvaguardar a proteção do direito à saúde. Por este motivo, existe uma grande questão por parte dos pacientes do Serviço Nacional de Saúde que não entendem o fato de existirem dificuldades no acesso e listas de espera.

Right to health in Portugal: legal delimitation of the National Health Service

Abstract: The right to health in Portugal is delimited by a legal basis inscribed in the Constitution of the Portuguese Republic of 1976 that materialized in 1979 through the creation of a National Health Service, which provides care in a universal, general and gratuitous manner. This article, through a review of the published legislation and the literature, intends to make known the legal framework of health in Portugal and its evolution over the years and current juridical delimitation.

Keywords: National Health Service. Constitution of the Portuguese Republic. Right to health.

Summary: Introduction - $\mathbf{1}$ The Constitutional right to health - $\mathbf{2}$ The creation of a National Health Service $\mathbf{-} \mathbf{3}$ The universality and generality of access to the Portuguese NHS $\mathbf{- 4}$ The gratuity in financing of the NHS - Conclusions - References

\section{Referências}

ADMINISTRAÇÃO CENTRAL DO SISTEMA DE SAÚDE (ACSS). Circular normativa no 8- Alteração do regulamento de aplicação de taxas moderadoras. Lisboa: Ministério da Saúde, 2016.

CAMPOS, António. Reformas na saúde - O fio condutor. Coimbra: Almedina, 2008. 
CAMPOS, Correia de; RAMOS, Francisco. Contas e ganhos na saúde em Portugal. Dez anos de percurso. Desafios para Portugal. Lisboa: Presidência da República, 2005.

CANOTILHO, J. Gomes; MOREIRA, Vital. Constituição da República portuguesa anotada. 3. ed. Coimbra: Coimbra, 2007.

COMISSÃO CONSTITUCIONAL PORTUGUESA. Parecer no 35/82. Lisboa, 1982.

FERNANDES, Adalberto. A combinação público-privado em saúde: impacto no desempenho no sistema e nos resultados em saúde no contexto português. Lisboa: Universidade de Lisboa, 2015.

MIRANDA, Jorge; MEDEIROS, Rui. Constituição portuguesa anotada. Coimbra: Almedina, 2005. v. I.

NOVAIS, Jorge Reis. As restrições aos direitos fundamentais não expressamente autorizadas pela Constituição. Coimbra: Almedina, 2003.

NOVAIS, Jorge Reis. Constituição e serviço nacional de saúde. Direitos Fundamentais \& Justiça, v. 4, n. 11, p. 85-109, abr./jun. 2010.

NOVAIS, Jorge Reis. Direitos fundamentais: trunfos contra a maioria. Coimbra: Almedina, 2006.

NOVAIS, Jorge Reis. Os principios constitucionais estruturantes. Coimbra: Almedina, 2011.

NUNES, Alexandre. Reformas na gestão hospitalar. na análise dos efeitos da empresarialização. Lisboa: Universidade de Lisboa, 2016.

PORTUGAL. Decreto de 10/04 de 1976. Lisboa, 1976.

PORTUGAL. Decreto-Lei no 113/2011, de 29 de novembro. Lisboa, 2011.

PORTUGAL. Lei no 1/2005, de 12 de agosto. Lisboa, 2005.

PORTUGAL. Lei no 1/82, de 30 de setembro. Lisboa, 1982.

PORTUGAL. Lei no 1/89, de 8 de julho. Lisboa, 1989.

PORTUGAL. Lei no 1/97, de 20 de setembro. Lisboa, 1997.

PORTUGAL. Lei no 147/99, de 1 de setembro. Lisboa, 1999.

PORTUGAL. Lei no 166/99, de 14 de setembro. Lisboa, 1999.

PORTUGAL. Lei no 31/2003, de 22 de agosto. Lisboa, 2003.

PORTUGAL. Lei no 4/2015, de 15 de janeiro. Lisboa, 2015.

PORTUGAL. Lei no 47/90, de 24 de agosto. Lisboa, 1990.

PORTUGAL. Lei no 56/79, de 15 de setembro. Lisboa, 1979.

PORTUGAL. Lei no 7-A/2016, de 30 de março. Lisboa, 2016.

PORTUGAL. Portaria no 311-D/2011, de 27 de dezembro. Lisboa, 2011. 
SIMÕES, Jorge; BARROS, Pedro; PEREIRA, João. A sustentabilidade financeira do Serviço Nacional de Saúde. Lisboa: Ministério da Saúde, 2008.

TRIBUNAL CONSTITUCIONAL. Acórdão no 330/89, de 11 de abril. Lisboa, 1989.

TRIBUNAL CONSTITUCIONAL. Acórdão no 39/84, de 5 de maio. Lisboa, 1984.

VALE, Luís Meneses do. A jurisprudência do Tribunal Constitucional sobre o acesso às prestações concretizadoras do direito à protecção da saúde: alguns momentos fundamentais. Jurisprudência Constitucional, Coimbra, n. 12, p. 12-47, 2006.

Informação bibliográfica deste texto, conforme a NBR 6023:2002 da Associação Brasileira de Normas Técnicas (ABNT):

NUNES, Alexandre Morais. Direito à saúde em Portugal: delimitação jurídica do Serviço Nacional de Saúde. Direitos Fundamentais \& Justiça, Belo Horizonte, ano 11, n. 37, p. 17-34, jul./dez. 2017.

Recebido em: 06.02.2017

Pareceres: 15.05.2016 e 13.06.2017

Aprovado em: 17.10.2017 